\title{
0 idealismo transcendental segundo Schopenhauer: de Berkeley para além de Kant
}

\author{
Transcendental idealism according to Schopenhauer: from Berkeley \\ to beyond Kant
}

\section{Dax Moraes*}

Universidade Federal do Rio Grande do Norte, Natal, RN, Brasil

\section{Resumo}

Sabe-se que Schopenhauer louva Berkeley como um grande idealista ao lado de Kant, seu principal inspirador. Schopenhauer, por sua vez, não segue o caminho kantiano, antes elaborando uma dura crítica da Analítica Transcendental e reformulando profundamente a doutrina do conhecimento intuitivo. De Berkeley, Schopenhauer toma a tese de que "ser é ser percebido", que, em suas palavras, corresponde à sentença "o mundo é minha representação". Apesar disso, são poucas as vezes em que Berkeley é mencionado por Schopenhauer ainda que se trate de importantes ocasiões. Isso talvez possa servir como explicação para o estranho fato de ser tão raro encontrar o nome de Berkeley nos estudos sobre a metafísica ou a teoria do conhecimento de Schopenhauer, exceto como casuais alusões àquelas breves menções. Diante disso, o presente artigo consiste em uma introdução à seguinte tese: o idealismo transcendental de Schopenhauer 
desenvolve o pensamento berkeleyano, utilizando-se do ponto de vista kantiano, de maneira a levar este último à consequência que Kant teria querido evitar.

Palavras-chave: Idealismo transcendental. Imaterialismo. Representação. Percepção.

\section{Abstract}

It is well known that Schopenhauer praises Berkeley as a great idealist philosopher beside Kant, his more notable inspirer. On the other hand, Schopenhauer does not follow Kantian path, but offers a hard critique on Transcendental Analytics instead and deeply reformulates his doctrine about intuitive knowledge. From Berkeley, Schopenhauer borrows the thesis according to which "to be is to be perceived". In his own words - "the world is my representation". Berkeley is although mentioned just a few times by Schopenhauer in some rather relevant occasions. Perhaps it could explain the strange fact that it is very rare finding the Berkeley's name while studying Schopenhauer's metaphysics or theory of knowledge but as a casual allusion to Schopenhauer's brief mentions. This paper is so an introduction proposing the following thesis: Schopenhauer's transcendental idealism develops Berkeley's thought by the means of a Kantian point of view leading the latter to consequences Kant would like to avoid.

Keywords: Transcendental idealism. Immaterialism. Representation. Perception.

A teoria do conhecimento elaborada por Schopenhauer sob a rubrica de "idealismo transcendental", como se sabe e é profusamente enfatizado pelo filósofo, inspira-se diretamente na filosofia crítica de Kant. Muito embora se apresente como ponto de partida de toda a sua doutrina, não consiste no tema schopenhaueriano mais comumente estudado, sobretudo no que concerne à originalidade das revisões propostas por Schopenhauer à filosofia especulativa de Kant, no esforço de preencher lacunas e solucionar os problemas deixados em aberto ou que não teriam sido adequadamente abordados pelo último. Nesse ínterim, o presente artigo tem como meta sugerir a pertinência de se incluir no diálogo o pensamento de Berkeley, que, apesar de também 
ter deixado problemas até certo ponto resolvidos por Kant, tendo parte significativa de sua contribuição deixada de lado, foi expressamente levado a sério por Schopenhauer. Desse modo, o estudo conjunto desses autores se configura como um resgate da importância de Berkeley na construção do idealismo transcendental, uma vez que Schopenhauer retoma o essencial de sua doutrina em sua polêmica não apenas contra o realismo materialista como também contra o próprio Kant. Em síntese, a tese berkeleyana de que "ser é ser percebido" vem a coincidir com a schopenhaueriana afirmação de que "o mundo é minha representação", que, por sua vez, contradiz o resíduo materialista, persistente em Kant, segundo o qual o fenômeno percebido deve ser pensado como remetendo a uma objetividade absoluta, embora incognoscível. Ainda que Kant tenha solucionado o problema da ciência, mostrando como pode haver conhecimento universalmente válido da Natureza, deixou intocado o problema fundamental do empirismo que constitui a verdadeira fonte do ceticismo: a pressuposição de um objeto em si, absolutamente distinto do objeto percebido. Para Schopenhauer, o em-si não é de modo algum um objeto; para Berkeley, semelhante suposição é um contrassenso.

\section{0 parricídio contra Kant}

É sabido que Schopenhauer se intitulava não um simples discípulo, mas o mais fiel continuador da filosofia de Kant, considerando filósofos idealistas como Fichte, ao contrário, falsificadores. No entanto, não apenas se mostra um crítico incondicional de Kant como propõe modificações que chegam mesmo a desfigurar o projeto filosófico do mestre, não obstante o fato de outros filósofos alemães de seu tempo não haverem procedido diferentemente, como é, de fato, o caso de Fichte. Nesse ínterim, Schopenhauer surge como alguém claramente nutrido pela intenção de superar o mestre. A Kant, Schopenhauer dirige sua "Crítica da filosofia kantiana", publicada como apêndice à sua obra capital, $O$ mundo como vontade e representação, de 1818/1819. Todavia, o "parricídio" pode ser encontrado logo no início do primeiro livro dessa obra e se caracteriza por uma revisão cujo resultado é de que a intuição deixa de ser "sob conceitos". O entendimento não mais 
aparece como faculdade racional para se tornar uma faculdade autônoma segundo a qual objetos são dados ao intelecto de modo pré-discursivo. Em outras palavras, na contramão de toda a tradição filosófica, o entendimento é apresentado como uma faculdade comum a todos os animais. Mais do que isso, perde seu sentido autêntico a noção de "sensibilidade pura" no que concerne à percepção de objetos, pois as formas kantianas da sensibilidade (tempo e espaço), apresentadas em sua Estética Transcendental, não são bastantes para tanto; assim, o conhecimento sensível incorpora uma única das categorias kantianas do entendimento (a causalidade) e despreza todo o resto da Analítica Transcendental.

O correlato subjetivo do tempo e espaço neles mesmos, como formas vazias, Kant denominou sensibilidade pura, expressão que pode ser conservada, pois Kant abriu o caminho, embora ela não seja apropriada, visto que a sensibilidade já pressupõe a matéria. $\mathrm{O}$ correlato subjetivo da matéria, ou causalidade, pois ambas são uma coisa só, é o entendimento, que nada é além disso. Conhecer a causalidade é sua função exclusiva [...]. A primeira e mais simples aplicação, sempre presente, do entendimento é a intuição do mundo efetivo [wirklichen Welt]. Este é, de fato, conhecimento da causa a partir do efeito; por conseguinte, toda intuição é intelectual [daher ist alle Anschauung intellektual] (SCHOPENHAUER, 2005, §4, p. 53).

Com isso, ainda, os sentidos tampouco podem ser considerados como fontes autônomas a produzirem sensações no sistema nervoso, uma vez que cada sensação requer, para ser percebida, uma atividade do intelecto, tal como é claramente argumentado por Schopenhauer no segundo capítulo dos complementos à obra capital. Dito de outro modo, a sensação pode ser considerada como um efeito mecânico objetivo, mas a crítica da intuição empírica revela que esse efeito mesmo é uma representação do entendimento, sendo apenas segundo sua conformação dos dados sensíveis que algo aparece como afetando os órgãos sensoriais. Aliás, não poderia ser diferente, uma vez que esses órgãos são partes de um corpo que não passa de aparência, fenômeno visível da vontade. O trecho citado é de uma intensidade ímpar, contando-se que o leitor esteja munido do mínimo conhecimento necessário para compreender o impacto avassalador dessas palavras para o projeto final kantiano. 
Percebe-se, de um lado, a caráter (talvez orgulhosamente) indulgente com que Schopenhauer concorda em manter a terminologia kantiana nesse passo, por reconhecimento do mérito de seu precursor. Por outro lado, a mantém sob uma condição de grande monta: trazer o entendimento para a estrutura transcendental da sensibilidade, desligando-o da estrutura transcendental do pensamento. O que se segue, para não soar arbitrário e enigmático, requer consideração dos termos envolvidos.

A sensibilidade pressupõe a matéria não no sentido de que toda sensação é sensação de um objeto exterior material e, como tal, substancialmente distinto do intelecto. A sensação é, em verdade, uma intuição, e tal intuição não é dita, consequentemente, "sensível", mas intelectual. (Evidentemente, não "intelectual" no sentido em que Schopenhauer refuta o intelectualismo e a filosofia de Fichte, fato que leva a maioria dos estudiosos a dizer o contrário: que, para Schopenhauer, toda intuição é sensível, tal como nos também refutados empiristas). Intuição, portanto, é a sensação de um objeto no intelecto; todavia, não a apreensão de um suposto objeto puramente inteligível (o que, por sua vez, faz emergir o problema do estatuto epistemológico das Ideias enquanto objetos do conhecimento estético, do que não poderei me ocupar aqui, além de exceder o escopo do presente artigo). Tal objeto "sensível" é o material da intuição, ou seja, algo que é dado como fazendo-efeito sobre os sentidos. Tal objeto, por sua vez, tem como correlato subjetivo a faculdade pela qual ganha sua configuração atual, o entendimento. Assim, de acordo com Schopenhauer, se chama matéria aquilo que aparece para nós no entendimento como fazendo-efeito, atuando (wirken), consistindo nisso toda a realidade (ou efetividade) (Wirklichkeit) do mundo (SCHOPENHAUER, 2005, §4, p. 50). O objeto é então entendido como efeito de um objeto dado como causa exterior. Tal atuação é o que se entende por matéria, a qual começa e termina no tempo, sendo dada a nós como causa externa em virtude da forma do espaço. Eis o que também se lê ao fim do primeiro capítulo do tratado Sobre a visão e as cores:

Ser equivale de fato a atuar; por isso, em alemão, diz-se com toda a exatidão e um profundo sentido inconsciente que tudo o que é, é real (wirklich), ou seja, é atuante (wirkend). [...] [A cor] é e permanece sendo o efeito exercido no olho, e o objeto é visto apenas como a causa; a cor 
em si, porém, é somente efeito, é o estado produzido no olho e como tal depende do objeto que só existe para o intelecto, pois ver é sempre um ato intelectual (SCHOPENHAUER, 2003a, §1, p. 47).

Nessas linhas gerais, pois, é que se deve entender a estranha doutrina schopenhaueriana ao dizer que causalidade é o mesmo que entendimento (aspecto subjetivo) e matéria (aspecto objetivo), bem como a união das formas de tempo e espaço. Na intuição, tempo, espaço e causalidade são indissociáveis. Pela abstração, todavia, não apenas se separa tempo, espaço e causalidade, mas também se separa o objeto intuído de um possível correlato exterior subsistente em si mesmo. (O tratamento mais amplo a essa questão é dado por Schopenhauer (1991) no longo §21 de sua tese, inserido na segunda edição sob o título "Aprioridade do conceito de causalidade - Caráter intelectual da intuição empírica - O entendimento", que termina com estabelecimento da linha que separa o autor da concepção kantiana).

Esse movimento se mostra como o de um retorno parcial ao que professavam os empiristas britânicos tão prezados por Schopenhauer, na medida em que restabelece a intuição como percepção de objetos materiais, em oposição aos idealistas alemães. No entanto, para Schopenhauer, o equívoco do empirismo se revela em seu materialismo, ou seja, no pressuposto de que exista por si mesma uma matéria, e, por conseguinte, na absurda e até então incontornável consequência, que Kant pretendera evitar: o ceticismo. A superação de ambos, materialismo e ceticismo, não deve se dar pela mera postulação de uma coisa-em-si entendida como objetividade absoluta (ou objetividade do objeto), cuja cognoscibilidade possa ser dispensada no conhecimento da Natureza, mas pela demonstração de que todo objeto possível é sempre objeto para um sujeito, forma fundamental, segundo Schopenhauer, do princípio de razão suficiente. Isso significa que um "objeto incognoscível" não passa de noção vazia. Desse modo, todo objeto é de natureza estritamente intelectual, porém não no sentido do idealismo fichteano, como produto da imaginação de um Eu Absoluto, pois a recíproca é verdadeira: todo sujeito é sujeito do conhecimento de objetos. Tratase, portanto, de estabelecer uma compreensão inteiramente outra de 
matéria e, por extensão, de realidade e causalidade, de maneira que o próprio significado do que seja um corpo se altera drasticamente.

Diante disso, cabe uma observação sobre o significado de "Vorstellung". Já se pode compreender que o termo, em Schopenhauer, não deve nomear um correlato subjetivo de um objeto em si: a representação é o mesmo que o objeto, a coisa tal como aparece enquanto aparece, sendo antes sinônimo de objeto e correlato direto do latim "objectum" - a Vontade não é objeto, uma vez que se encontra fora do princípio de razão, não sendo, portanto, coisa-em-si nesse sentido. Sendo assim, a tradução por "representação" não deve ser de modo algum admitida sem reservas a fim de que não se confunda, como em geral ocorre dentre os críticos, com acepções realistas ou céticas, cada qual supondo à sua maneira um objeto distinto do representado. Japiassú e Marcondes (1996, p. 235, grifos meus), por exemplo, escrevem sobre o conceito de "representação" nos seguintes termos:

Operação pela qual a mente tem presente em si mesma uma imagem mental, uma ideia ou um conceito correspondendo a um objeto externo. A função da representação é exatamente a de tornar presente à consciência a realidade externa, tornando-a um objeto da consciência, e estabelecendo assim a relação entre a consciência e o real. [...] A principal dificuldade parece ser o pressuposto de que a consciência seria incapaz de apreender diretamente o objeto externo.

É precisamente a dificuldade apontada no final que se vê eliminada por Schopenhauer e, antes dele, por Berkeley, ou seja, o desmascaramento do pressuposto realista de que se origina o subterrâneo ceticismo que ameaça todo empirismo e todo intelectualismo dualista. Não há correspondência - melhor dizendo, nada há com que se estabelecer essa relação, já que todo objeto real - não mera fantasia da imaginação - não pode ser senão objeto intelectual. Desse modo, a partícula "re-" herdada do latim induz ao erro de tomar o objeto no entendimento como um segundo a aparecer mediante a presença de um outro algo - a coisa "em si". Assim como Schopenhauer desculpa Kant pela inconsequente expressão "sensibilidade pura", ele mesmo talvez deva ser desculpado pelo emprego de um termo que, de fato, pareceria querer significar a repræsentatio, sendo ainda tratado de modo ambíguo por 
Kant, conforme nos diz Caygill (2000, p. 280-281). No contexto da obra schopenhaueriana, a melhor justificativa para a tradução "representação" seria apelar às suas reiteradas analogias entre o mundo e um palco de teatro, ou seja, o espaço no qual desfilam as aparências do ser, como em um baile de máscaras, mas o teatro somos nós mesmos. Não que "o ser" seja um outro; nós é que só o vemos e conhecemos tal como se mostra em nós, mas sem nenhuma existência independente desse "nós". Finalizando essa observação que já se tornou extensa, cabe compreender que, aqui, não cabe à representação a função de "tornar a realidade objeto da consciência", antes o contrário: a Vorstellung consiste em fazer do objeto intuído na consciência uma coisa real no mundo externo, não como causa dessa intuição no sentido corrente, mas como o projetado e exposto diante de nós segundo as formas do tempo e do espaço.

\section{0 retorno a Berkeley}

Segundo Schopenhauer, Kant não seguiu o devido caminho imposto por sua própria crítica da razão, chegando mesmo a desfigurar sua obra quando de sua reedição em 1787. Schopenhauer chega a dizer - dando suporte à hipótese levantada aqui - que Kant teria tido "temor em face do idealismo berkeleyano" (SCHOPENHAUER, 2005, p. 560). Nesse ponto, pode-se dar razão a Schopenhauer se observarmos as supressões feitas por Kant na segunda edição da obra, destacando-se, como exemplo, o que dissera antes, demoradamente, a respeito do quarto paralogismo (A 367 et seq.).

Desse modo, Schopenhauer pode ser remetido ao peculiar idealismo de Berkeley, que, também buscando vencer materialistas e céticos, leva às últimas consequências as premissas do empirismo, cuja primeira é: toda percepção é percepção de algo sensível, e tais objetos sensíveis somente são conhecidos na condição de ideias em um intelecto. Essa tese permite um paralelo exato com a afirmação inicial de Schopenhauer em sua obra capital: "O mundo é minha representação" - o próprio Schopenhauer o admite (SCHOPENHAUER, 2005, §1, 
p. 44; CARTWRIGHT, 2005, p. 14). Isso à parte, com a ressignificação do conceito de "matéria", Schopenhauer dá outro sentido ao conceito de "ideia" corrente em sua época, razão pela qual diz usar esse termo no sentido filosófico originário, "platônico" (SCHOPENHAUER, 2005, §25, p. 191). De todo modo, até aqui, a diferença entre Berkeley e Schopenhauer reside mais nas palavras do que no conteúdo mais essencial das doutrinas. Não que se trate de uma diferença desprezível, uma vez que pode produzir confusões. Exemplo disso é a tradução de J. Berman da obra capital para o inglês (The world as will and idea), sendo todavia digno de nota, nesse contexto, que o conceito schopenhaueriano de "Vorstellung" tampouco se vê adequadamente traduzido pelo termo "representação" - dominante em todas as línguas - , conforme observado há pouco. Portanto, pode-se dizer que as teses de Schopenhauer e Berkeley coincidem "em espírito", em significado, com relação a esse ponto decisivo. Segundo Berkeley, no começo do Tratado sobre os princípios do conhecimento humano, §5:

Afinal, pode haver uma maneira mais sutil de abstração do que distinguir a existência dos objetos sensíveis do seu ser percebido, assim como concebê-los existindo impercebidos? [...] Para mim é fácil separar uma coisa dela mesma. [...] Mas meu poder de conceber ou imaginar não se estende, entretanto, para além da possibilidade da real existência, ou percepção. Por isso, assim como é impossível ver ou sentir algo sem uma sensação efetiva dele, também é impossível conceber em meus pensamentos uma coisa sensível ou objeto diferente de sua sensação ou percepção (BERKELEY, 2010, p. 60).

Ou seja, Berkeley já havia se dado conta de que todo objeto real é ao mesmo tempo sensível - enquanto é percebido - e intelectual - considerada sua natureza ideal. Dito de outro modo, não pressupõe a existência exterior de uma coisa de cuja sensação o entendimento abstrairia uma ideia. Em vez disso, a ideia no intelecto é a coisa e abstratas seriam as divisões das partes reconhecidas na coisa percebida como unidade, conforme se lê no Terceiro Diálogo: "Não sou a favor de transformar as coisas em ideias, mas, antes, as ideias em coisas, pois esses objetos imediatos da percepção, os quais de acordo com você 
são só aparências das coisas, eu as tomo como as coisas reais em si" (BERKELEY, 2010, p. 289). Afinal, a designação "ideia" remete à natureza intelectual dos objetos, não sendo, conforme o §38 do Tratado, "usada na linguagem ordinária para designar as diversas combinações de qualidades sensíveis chamadas de coisas" (BERKELEY, 2010, p. 81), como pretendera Locke. Mais adiante no Tratado, §90, Berkeley (p. 116) afirma que "ideias impressas nos sentidos são coisas reais, ou existem realmente", mas que isso não significa que "possam subsistir fora da mente que as percebe [...] visto que o próprio ser de uma sensação ou ideia consiste em ser percebido". Não há, portanto, prossegue ele, um correlato externo às ideias/sensações/percepções/coisas reais na medida em que "uma ideia não pode assemelhar-se a nada senão a outra ideia", podendo apenas "ser denominadas de externas no tocante à sua origem, na medida em que não são geradas internamente, pela própria mente" como é o caso do que é produzido pela imaginação ou pela memória. Desse modo, percepção interna e percepção externa, ou melhor, a ideia concebida como de uma coisa existente no interior ou no exterior são relativas meramente ao modo de operação do sujeito do conhecimento. Falta a Berkeley uma explicação suficiente, oferecida por Kant e tomada por Schopenhauer para corrigir a ambos, sobre segundo o que um objeto na mente possa ser dado a priori como exterior ao corpo e mesmo como é possível ter um corpo, no sentido de que ao abrir meus olhos, os objetos visíveis já se encontram diante deles como se já estivessem ali. Berkeley parece reconhecer essa dificuldade, tendo de apelar a um outro espírito que produza as ideias que não são originadas internamente, sem, contudo, cair na armadilha realista de um mundo objetivo criado de fato como existente em si mesmo - a criação não poderia ter outro lugar senão no espírito do criador.

Apesar disso, são muito poucas as ocasiões em que Schopenhauer se refere a Berkeley, não obstante cada menção seja profundamente significativa e, ademais, ocorra com maior frequência na "Crítica da filosofia kantiana". Não é, de fato, tão difícil encontrar na literatura especializada reproduções dessas menções, sendo, no entanto, raro que sejam aprofundadas e, quanto a uma estrita tematização, a literatura apresenta uma surpreendente lacuna. Mesmo a tese de doutorado de Eduardo 
Brandão, sobre o conceito de matéria em Schopenhauer, posteriormente publicada em livro (BRANDÃO, 2009), concentra-se, no que tange a essa questão em particular, no confronto entre Schopenhauer e Locke, este último tomado por Berkeley como seu rival, por assim dizer, não trazendo à cena a tese berkeleyana. Antes disso, o inaugural e perenemente relevante trabalho de Maria Lúcia Cacciola (1994), Schopenhauer e a questão do dogmatismo, referência para se compreender o projeto filosófico de Schopenhauer, já deixava um lugar vago para um diálogo com Berkeley, que talvez seja para a compreensão desse filósofo - assim defendo mais importante dentre os britânicos do que Locke, cujo mérito fora, antes, preparar o caminho a ser seguido por Kant (SCHOPENHAUER, 2015, cap. 4, p. 49; 2014, I, p. 93). O único artigo encontrado sobre o assunto, escrito por um estudante de mestrado (MOREIRA, 2010), opta por destacar as diferenças, atendo-se excessivamente ao lugar da realidade material na Filosofia da Natureza de Schopenhauer, desconsiderando indevidamente tratar-se aí, unilateralmente, do ponto de vista objetivo - falta grave, pois o problema da Natureza, em Schopenhauer, consiste precisamente em desvelar a essência das forças naturais a fim de que se possa elucidar os seus fenômenos, advogando a necessidade de uma metafísica como complemento ineludível das ciências positivas.

Uma hipótese explicativa para esse fato é a de que Berkeley não seja tão estudado quanto outros filósofos britânicos, sobre os quais há prolíficas referências, tais como Hobbes, Locke, Hume, apenas para citar os mais eminentes. Como agravante, a obra de Schopenhauer, por mais célebre que seja, não é estimada - deve-se admitir - como pertencente às filosofias de "primeira linha". Dentre seus estudiosos, por sua vez, o foco principal incide sobre os temas de Ética, que se estendem aos subtemas da negação da vontade, do pessimismo - questões que movem especialmente os diálogos com o pensamento de Nietzsche da sabedoria de vida. Esses temas, em importância, quantitativamente, são imediatamente seguidos pelos temas de Estética. Nesse quadro, as questões estritamente gnosiológicas aparecem, no mais das vezes, de modo transversal, ou ainda sob abordagens muito particulares, desprezando-se, por exemplo, seu cunho, poder-se-ia dizer, fenomenológico. Muito do que se escreve sobre Schopenhauer termina se atendo 
ao que, para muitos que só têm um conhecimento fragmentário de seu pensamento, é algo, se não inconsistente, extravagante, deixando-se de lado elementos de extrema significância para a história das ideias. Exemplo disso é a interpretação equivocada de que se pode ter um conhecimento imediato da coisa-em-si tal como ela é em si mesma, que é uma Vontade, e que tal conhecimento consiste em um saber presente no pensamento oriental capaz de redimir o mundo. Aliás, é por conseguinte comum se destacar a possibilidade desse conhecimento como a principal inovação com relação a Kant, passando-se por cima da completa reconfiguração do conhecimento intuitivo e suas consequências mais significativas. O reiterado rótulo "filósofo do pessimismo" não deixa de ser também um empecilho, na medida em que tende a atrair para si interesses filosóficos de segunda ordem e de impacto científico reduzido, ao menos se se desconsidera em que se enraíza esse dito pessimismo, tema a que me dedico em outros trabalhos.

Em parte, a desconsideração de Berkeley nesse diálogo pode ser remetida ao que diz Schopenhauer no prefácio da segunda edição de O mundo como vontade e representação, a saber, que sua filosofia "parte da kantiana", que "permite remover o realismo inato creditável à determinação originária do intelecto, para o que nem Berkeley nem Malebranche são competentes"' (SCHOPENHAUER, 2005, p. 33-34). Por sua vez, a necessidade de um retorno a Berkeley é evidente quando se pretende compreender o que faltou a Kant para dar o devido acabamento ao impulso iniciado pelo filósofo irlandês, ou mesmo por Locke antes dele. Para admiti-lo, talvez baste o que se lê na "Crítica da filosofia kantiana": o caráter infundado da distinção entre a representação e o objeto da representação já havia sido demonstrado por Berkeley, sendo o que resulta da própria exposição de Schopenhauer, enquanto a inserção injustificada do objeto da representação por Kant é a fonte de seus erros (SCHOPENHAUER, 2005, p. 557), não tendo sido Kant justo em relação aos méritos de Berkeley, além de entrar em contradição consigo mesmo na segunda edição da Crítica da razão pura (SCHOPENHAUER, 2005, p. 546). No "Esboço de uma história da teoria do ideal e do real", Berkeley é apresentado como "autor do verdadeiro e próprio idealismo" (SCHOPENHAUER, 2003b, p. 32), repetindo 
o louvor a seu pioneirismo nos "Fragmentos sobre a história da filosofia” (SCHOPENHAUER, 2003b, p. 116). Nesse sentido, cabe explorar em que consiste a limitação da perspectiva de Berkeley, o que, em Kant, segundo Schopenhauer, serve para levá-la a bom termo e estabelecer uma versão mais consistente do idealismo. Nesse sentido, pode-se ler no primeiro capítulo do segundo tomo de sua obra capital, as palavras do próprio Schopenhauer sobre a pertinência dessa relação e do resgate desse retorno a Berkeley se quisermos ser consequentes na compreensão do projeto antirrealista de Schopenhauer:

A filosofia de Locke foi a crítica das funções dos sentidos; Kant, entretanto, fez a crítica das funções do cérebro. - Entrementes, é preciso ainda adicionar a tudo isso o resultado da filosofia de Berkeley, por mim renovado, vale dizer, que todo objeto, não importa a sua origem, já como objeto é condicionado pelo sujeito, que[r] dizer, essencialmente não passa de sua representação. (SCHOPENHAUER, 2015, p. 14; grifo meu)

É possível arriscar, portanto, que o assunto seja de importância irrecusável para que se lance a devida luz sobre a natureza do "pensamento único" de Schopenhauer. Afinal, o fato de, segundo ele mesmo, poder adentrar a seu sistema por qualquer parte, não significa possa ser bem-sucedido sem a adequada compreensão daquilo sobre o que tudo se sustenta, de modo que, didaticamente, é o primeiro na ordem expositiva de sua obra capital.

\section{Para além de Kant}

Com efeito, elementos da filosofia de Berkeley já são superados por Kant, como, por exemplo, o recurso a um intelecto infinito que garanta a existência das ideias não atualmente percebidas pelos intelectos finitos, o que chegara a ser utilizado pelo primeiro como prova da existência de Deus. A impossibilidade da prova da existência de Deus à luz dos resultados da crítica da razão obriga Kant a admitir que todo o conhecimento propriamente dito deve ser restrito ao fenômeno percebido pelo sujeito, muito embora Kant mantenha o próprio Deus como uma ideia. Todavia, a 
análise do conhecimento o conduz à hipótese de uma subjetividade transcendental capaz de intuições cuja validade é estabelecida a priori, segundo regras que, por sua vez, determinariam a possibilidade de se pensar os fenômenos conhecidos como causados por ou remissíveis a coisas-em-si incognoscíveis. Essa alternativa preveniria contra o ceticismo combatido por Berkeley na medida em que os objetos do conhecimento, na ausência de um criador cuja existência não se pode demonstrar racionalmente - o mesmo valendo para a realidade do mundo externo - , pudessem ser remetidos a uma superestrutura cognoscitiva comum a todos os seres racionais: o sujeito transcendental, uma espécie de reformulação do “Eu penso" cartesiano. Com isso, o fenômeno recebe novo fundamento externo ao sujeito, embora seja como uma construção sua.

Schopenhauer não se satisfaz com essa alternativa, acusando Kant de haver infringido seus próprios princípios ao aplicar a categoria de causalidade àquilo que não é representação, expediente que teria comprometido ainda mais seriamente sua filosofia moral. A crítica se justifica perfeitamente no contexto da antinomia da razão, quando Kant, sob o título "Possibilidade da causalidade por liberdade em união com a lei universal da necessidade natural" (B 566-7), chega à formulação de uma causalidade considerada "inteligível no que diz respeito à sua ação como uma coisa em si mesma", "que não é fenômeno, muito embora o seu efeito seja encontrado no fenômeno" (KANT, 2013, p. 432). Embora essa interpretação seja questionável e problemática, como bem nota Cacciola (1994, p. 49), não obstante encontre a divergência no que diz respeito ao caráter inteligível (1994, p. 103-104), a eventual problematicidade da crítica não interfere no desdobramento positivo que coloca Schopenhauer e Berkeley de acordo contra Kant: não havendo objeto correlato à Vorstellung, pois todo objeto é objeto percebido, não se pode atribuir realidade objetiva alguma à coisa-em-si, nem empírica nem lógico-formal. Schopenhauer mantém a distinção entre fenômeno e coisa-em-si como mérito principal da crítica kantiana, mas não sem modificar profundamente o modo de consideração dessa distinção, rumo a uma perspectiva de caráter monista, tal como enfatizado por Jules de Gaultier em artigo de 1904: "Em oposição a todo sistema dualista, sua concepção do universo é expressamente monista" (GAULTIER apud BRUM, 1998, p. 56, n. 5). A esse respeito, o segundo capítulo do livro de Cacciola (1994), "A teleologia e a 
questão das causas finais", oferece uma acurada discussão e, além disso, mais adiante, Cacciola sintetiza com clareza o sentido primordial da distinção entre vontade e fenômeno, pela qual Schopenhauer "bane de uma vez por todas a noção de uma inteligência que impusesse seus fins ao mundo" (p. 102), não havendo, pois, algo externo ao mundo, mera visibilidade da essência universal para nós. Vale observar que a dicotomia - geralmente denominada "dualismo" - entre Vontade e Representação, não diz respeito a duas realidades distintas, mas ao ser verdadeiro e seu lado aparente. Em carta a Frauenstädt de 14 de agosto de 1856, Schopenhauer lhe escreve: "quando digo: a lua tem dois lados, um dos quais vemos, o outro nunca: isto é dualismo? - Fenômeno e coisa-em-si - Vontade e representação tampouco o são" (SCHOPENHAUER apud CACCIOLA, 1994, p. 53, n. 69). Sua alternativa, então, para o problema de Berkeley - como é possível a existência de ideias não atualmente percebidas - consiste em dizer que os fenômenos não são causados pela coisa-em-si, tanto menos por Deus, mas consistem em seu modo de manifestação no entendimento, para o que não pode haver fundamento algum.

O mundo é, assim, destituído de uma existência autônoma e separada, seja de que tipo for, mas isso não significa que esse mesmo mundo não possa ser considerado para além de um princípio de razão que já sempre o conforma aos modos de apreensão, isto é, para além da consciência objetiva. Ou seja, similarmente ao que defendera Berkeley, o que podemos saber das coisas é apenas sua existência para nós, e tal existência é precisamente aquela no intelecto, não havendo outro modo de as coisas existirem. $O$ " $x$ " desconhecido é, na verdade, o que age por detrás do ato sensível e isso só pode ser (re)conhecido mediante a demonstração de que todos os fenômenos representados no intelecto dependem não de algo que lhes sirva de causa, como queria Kant a seu ver, ou mesmo Berkeley (referindo-se a Deus como intelecto infinito), mas de algo que os preceda uma vez constituindo nosso próprio ser, independente, enquanto tal, do intelecto, conforme argumentado no capítulo 19 dos complementos a $O$ mundo como vontade e representação. Afinal, dizer que não há sujeito sem objeto não deve ser entendido como se um sujeito já não seja sempre subentendido como condição transcendental para o fenômeno objetivo. Um ente incapaz de perceber 
tampouco pode ter qualquer conhecimento sobre si mesmo, mas o fato de perceber objetos abre a possibilidade de um conhecimento de si, sempre indireto, não como de algo determinado - este é sempre um objeto - , mas de algo que conhece sem ser, por sua vez, conhecido diretamente como é em si, independentemente dos objetos que conhece. Tal conhecimento de si é um conhecimento de si como Vontade porque o contato com objetos sempre traz consigo um sentimento de agrado ou desagrado, de querer ou não querer o afeto produzido na presença dos mesmos. Nesse ponto, aliás, Berkeley (no Primeiro Diálogo) e mesmo Kant (na Crítica do juízo, §29) parecem concordar expressamente:

Tente de novo, Hylas, se você pode conceber em seus pensamentos uma sensação veemente sem ser com dor ou prazer (BERKELEY, 2010, p. 183).

[...] todas as representações dentro de nós, não importa se, de um ponto de vista objetivo, são meramente sensíveis ou totalmente intelectuais, ainda são subjetivamente associáveis à satisfação ou dor, por mais imperceptíveis que estas possam ser (KANT apud CAYGILL, 2000, p. 281).

[...] toda ação sobre o corpo é também simultânea e imediatamente ação sobre a vontade, que enquanto tal [i.e. subjetivamente] se chama dor, caso a contrarie, ou bem-estar, prazer, caso lhe seja conforme (SCHOPENHAUER, 2005, §18, p. 158).

Dito brevemente, fenomenologicamente Schopenhauer afirma que o sentimento de que se quer ou não se quer, de agrado e desagrado, jaz sempre ao fundo de toda e qualquer representação, o que afeta o sujeito não é em primeira instância um objeto, mas o ser imediatamente sujeito de prazer ou desprazer. Aquilo que nos é indiferente não nos afeta em si mesmo, como a luz, que, se não é forte demais (ofuscando a visão) nem de menos (dificultando a percepção), apenas nos mostra aquilo que, refletindo-a, faz efeito sobre alguma parte de nosso corpo - nesse caso particular, nossa retina. A propósito, o próprio movimento da pupila poderia ser compreendido como uma adequação espontânea do órgão manifestando relaxamento e tensão, cujos limites, uma vez ultrapassados, produziriam 
desde desconforto visual até cefaleia e mesmo náuseas ou desfalecimento. Esse "fazer-efeito" (wirken), ou causalidade, como já explicado acima, é precisamente o que Schopenhauer denomina o material, ou seja, o conteúdo de nossas representações, a realidade (Wirklichkeit) submetida, ou melhor, constituída segundo as formas do tempo e do espaço. Desse modo, a realidade, a "matéria", emerge de um efeito meramente sentido por meio do próprio corpo que recebe sua forma, também no intelecto, espaço-temporal. O ser-afetado por esse material é, ao mesmo tempo, o que nos dá a conhecer o nosso próprio corpo, de maneira que esse corpo pode ser considerando de modo ambivalente, a saber, como o que é conhecido imediatamente no fato de ser-afetado por objetos dados como exteriores, mas, em realidade, representados no intelecto, como algo fronteiriço entre mundo percebido e sujeito do conhecimento, que se percebe imediatamente apenas enquanto sendo afetado por algo, ou mediatamente, quando o próprio corpo é percebido objetivamente por seus próprios órgãos sensoriais.

Seguindo Kant, mas desenvolvendo de modo mais amplo o conceito de "matéria", Schopenhauer a toma como mera abstração dos materiais da experiência, mas não sem eliminar de modo ainda mais incisivo qualquer resíduo de uma correspondência possível entre a mesma e o fenômeno, o que é denominado "resto dogmático" por Cacciola (1994, p. 172; BRANDÃO, 2015, p. 214), que observa ser essa uma crítica herdade de Jacobi e Schulze (CACCIOLA, 1994, p. 48-49, n. 60). O que diz Caygill (2000, p. 226), que Kant teria “despojado a matéria de toda a dignidade que era conferida ao conceito na história da filosofia, não sendo a 'matéria em si' (hyle) nem mesmo a substância material subjacente a acidentes", é exatamente o que Berkeley diz, abrindo uma concessão final no terceiro diálogo entre Hylas e Philonous: "Conserve a palavra matéria aos objetos dos sentidos, se quiser, desde que não atribua a eles uma subsistência diferente do seu ser percebido" (BERKELEY, 2010, p. 315316). Nesse sentido, a contribuição de Kant, segundo a qual a existência dos objetos do conhecimento prescinde de um Criador, uma vez submetida ao ateísmo schopenhaueriano, é estendida à própria coisa-em-si, que deve ser pensada como livre não apenas de nossa estrutura cognitiva (o princípio de razão), mas também de qualquer relação causal com o fenômeno, que é nada além de sua aparência para nós e por nós conformada. 
Pode-se defender a hipótese de que, lendo Berkeley à luz da crítica kantiana e, assim, suprimindo os pressupostos teológicos, Schopenhauer pôde seguir um caminho distinto do de Kant, reformulando o idealismo transcendental de modo mais econômico, ou seja, dispensando toda a tortuosidade da arquitetônica (e seus inconvenientes) sem deixar de prover a proposta berkeleyana dos elementos suficientes à sua liberação do dogmatismo cristão. Por esta via, Schopenhauer ainda acreditava poder restabelecer o que considerava ser o projeto inicial de Kant na primeira edição da Crítica da razão pura (1781), sem temer os efeitos tornados indesejáveis para seu autor: que a crítica da razão conduzisse à inevitável radicalização do idealismo, levada a termo de modo tão equivocado por Fichte, segundo Schopenhauer.

O que faltava a Berkeley era a dimensão transcendental da filosofia crítica kantiana. Sem isso, Berkeley foi apenas capaz de converter a existência de Deus de pressuposto a uma condição demonstrável $a$ posteriori, deixando, todavia, intocada, por exemplo, a necessidade de um Criador ou intelecto infinito. O que a dimensão transcendental oferece é a constituição subjetiva e a priori dos objetos dos sentidos, os quais só podem ser percebidos e existentes mediante sua presença no intelecto, ou seja, o que diz Berkeley consistir em ideias em uma mente. Por sua vez, um idealismo radical leva a um solipsismo igualmente radical, de alcance ontológico e não apenas epistemológico - o caminho tomado por Fichte - se tais ideias (intuições) não se vinculam de algum modo a qualquer espécie de "realidade" independente do intelecto. Tal solipsismo é superado tanto por Berkeley (2010, §145, p. 156) como por Schopenhauer (2005, §19, p. 162-163), neste último por uma exigência moral, inclusive. O que, então, para Kant, deve ser pensado como coisa-em-si, absolutamente incognoscível, é, para Schopenhauer, relativamente cognoscível como Vontade. Como já observou Cacciola (1994, p. 58), contra um equívoco usual,

[...] se a Vontade se manifesta diretamente a cada indivíduo [consciente], isto ainda é um conhecimento fenomênico, por estar submetido ao tempo, condição da experiência interna [i.e. da sucessão dos estados sem pressuposição de uma exterioridade]. O conhecimento da essência esbarra, pois, na condição do conhecimento do fenômeno e, embora 
essa essência se manifeste sem mediações, ela não é plenamente conhecida, desde que permanece uma última barreira: a temporalidade.

Essa Vontade, certamente, não é um objeto real, tampouco possível, mas aquele Indeterminado e Incondicionado (por um princípio de razão) cuja atividade sobre o corpo do sujeito permitiria, por analogia, reconhecer, se não a realidade externa, ao menos a concretude essencial de todo fenômeno percebido, como indício de que não se está sozinho no mundo. A seguir, desvela-se que a realidade desse mesmo sujeito que percebe é tão fenomenal quanto suas representações (objetos), aposta que culminará no sentido moral da existência mediante o (re)conhecimento da unidade essencial da coisa-em-si, manifesta sob infinitas configurações no mundo fenomênico.

Mas não é apenas isso o que fornece a estrutura transcendental do conhecimento para cobrir as lacunas do idealismo de Berkeley. Este supunha bastar, em sua oposição ao empirismo lockeano, que estimava a matéria como uma coisa-em-si, demonstrar que a admissão de qualidades primárias inerentes aos objetos levava ao absurdo, uma vez que a matéria mesma que as carregaria não pode ser percebida. Desse modo, as ideias impressas no intelecto deveriam apresentar tais qualidades por terem sido assim encontradas na mente. Trata-se, porém, de uma afirmação dogmática e também infundada, pois, sem a doutrina da Estética Transcendental não há como explicar racionalmente que uma ideia - mera forma atemporal e inextensa - possa ser percebida de maneira espaço-temporal. A percepção é sempre de algo sensível, mas esse algo sensível sempre se dá em um tempo e lugar, bem como com limites, dotado de extensão, o que, por definição, é um corpo. Ao reformular a tese kantiana, dizendo que a sensibilidade requer a forma da causalidade, que Schopenhauer estima como sendo a única "categoria" do entendimento - a rigor, mera forma, jamais uma categoria, uma vez que se trata de uma intuição pré-discursiva, sem conceito -, este autor não apenas resolve o contrassenso da doutrina de Berkeley, do que advém a necessidade de ressignificação do conceito de "matéria". Desse modo, de uma vez, Schopenhauer, não Kant: a) restitui a Ideia ao seu sentido originário de objeto cuja determinação é atemporal e inextensa, logo, mera forma não sensível; b) corrige Berkeley ao demonstrar que a matéria, como objeto intuído, deve ser o nome próprio do que este último chamava "ideia", ainda 
nas raias do empirismo; e c) demonstra que uma só das doze categorias kantianas do entendimento é suficiente para que se tenha percepção objetiva. Vale acrescentar algo que a esta altura deve ficar claro quanto ao seu alcance: Berkeley (2010, §27, p. 75) também via o espírito sob uma dupla perspectiva, podendo ser, em cada caso, denominado segundo suas duas principais faculdades, a saber, entendimento e vontade. O paralelo com Schopenhauer é evidente, embora este não mais tome a vontade como "faculdade", sem prejuízo de concordar com Berkeley sobre a impossibilidade de haver uma "ideia" - isto é, uma representação real - da vontade, que também pode ser chamada "alma”, "espírito", "eu”, enfim, o sujeito do conhecimento, que conhece sem ser conhecido.

\section{Considerações finais}

Esta intrincada discussão, longe de poder ser esgotada nos limites deste artigo, uma vez recebendo o adequado aprofundamento, deve, conforme a hipótese apontada, levar à conclusão de que Schopenhauer, munido do instrumental fornecido pela filosofia crítica de Kant, dirige o idealismo transcendental a uma maturidade e simplicidade que o tornam ainda mais digno de consideração, tal como já é sob a problematização fenomenológica do século XX. Desse modo, o próprio pensamento schopenhaueriano pode ser rejuvenescido e atualizado de maneira a se tornar um importante referencial para estudos recentes em Filosofia da Mente, que vêm ganhando crescente destaque nas diferentes abordagens sobre o tema do enativismo, por exemplo. O resultado pretendido mais significativo - e dele decorre a exigência de uma reconsideração do lugar de Schopenhauer na metafísica e na epistemologia contemporâneas - haverá de ser a demonstração de que o estudo crítico-comparativo de Kant e Berkeley revela que ambos os filósofos, empenhados na superação do dogmatismo - i.e. suposições racionalmente ilegítimas - e atentos às limitações incontornáveis de nosso conhecimento, expostas pelos empiristas britânicos, têm seus esforços como que sintetizados e renovados na obra de Schopenhauer. O que Schopenhauer obtém por esse 
meio se mostra como precursor de uma nova compreensão do modo de operação da consciência e da natureza de seus conteúdos.

\section{Referências}

BERKELEY, G. Obras filosóficas. Trad. Jaimir Conte. São Paulo: UNESP, 2010. BRANDÃO, E. A concepção de matéria na obra de Schopenhauer. São Paulo: Humanitas, 2009.

BRANDÃO, E. Schopenhauer, leitor de Schulze: a questão do dogmatismo. In: FONSECA, E. R. et al. Dogmatismo \& antidogmatismo: filosofia crítica, vontade e liberdade. Uma homenagem a Maria Lúcia Mello e Oliveira Cacciola. Curitiba: UFPR, 2015. p. 213-224.

BRUM, J. T. O pessimismo e suas vontades: Schopenhauer e Nietzsche. Rio de Janeiro: Rocco, 1998.

CACCIOLA, M. L. M. e O. Schopenhauer e a questão do dogmatismo. São Paulo: EDUSP, 1994.

CARTWRIGHT, D. E. Historical dictionary of Schopenhauer's philosophy. Lanham (Maryland): Scarecrow, 2005. (Historical Dictionaries of Religions, Philosophies, and Movements, 55).

CAYGILL, H. Dicionário Kant. Rio de Janeiro: J. Zahar, 2000.

KANT, I. Crítica da razão pura. Trad. Fernando Costa Mattos. 3. ed. Petrópolis: Vozes; Bragança Paulista: EDUSF, 2013. (Coleção Pensamento Humano).

JAPIASSÚ,H.;MARCONDES, D. Representação. In: JAPIASSÚ,H.;MARCONDES, D. Dicionário básico de filosofia. 3. ed. rev. ampl. Rio de Janeiro: J. Zahar, 1996. p. 235.

MOREIRA, F. de S. Schopenhauer entre Locke e Berkeley. Argumentos: Revista de Filosofia - Programa de Pós-Graduação da UFC. Fortaleza, v. 2, n. 3, p. 5969, jan.-jun. 2010. Disponível em: < http://www.periodicos.ufc.br/argumentos/ article/view/18948 >. Acesso em: 23 dez. 2017. 
SCHOPENHAUER, A. Sämmtliche Werke. Ed. Julius Frauenstädt. Leipzig: Brockhaus, $1877.6 \mathrm{v}$.

SCHOPENHAUER, A. Arthur Schopenhauers Sämtliche Werke in 12 Bänden. Mit einer Einleitung von Dr. Rudolf Steiner. Stuttgart: Cotta, 1894-1896.

SCHOPENHAUER, A. Sämtliche Werke. Edição e comentários críticos por Wolfgang Frhr. von Löhneysen. Stuttgart; Frankfurt am Main: Cotta-Insel, 1960-1965. 5 v.

SCHOPENHAUER, A. De la quadruple racine du principe de raison suffisante. Trad. para o francês por F.-X. Chenet. Introduções e comentários de F.-X. Chenet e M. Piclin. Paris: J. Vrin, 1991. Edição completa, contendo a versão original de 1813 e a definitiva de 1847. (Bibliotèque des Textes Philosophiques).

SCHOPENHAUER, A. Sobre a visão e as cores. Trad. Erlon José Paschoal. São Paulo: Nova Alexandria, 2003a.

SCHOPENHAUER, A. Parerga e paralipomena: scritti filosofici minori. v. I. Ed., pref. e trad. Giorgio Colli. Firenze: Adelphi, 2003b.

SCHOPENHAUER, A. O mundo como vontade e como representação: primeiro tomo. Trad. Jair Barboza. São Paulo: UNESP, 2005.

SCHOPENHAUER, A. O mundo como vontade e representação. Trad. Eduardo Ribeiro da Fonseca. Curitiba: UFPR, 2014. 2 v. Tomo II: Complementos.

SCHOPENHAUER, A. O mundo como vontade e como representação: segundo tomo. Trad. Jair Barboza. São Paulo: UNESP, 2015.

Recebido: 18/01/2018

Received: 01/18/2018

Aprovado: 26/01/2018

Approved: 01/26/2018 